\title{
CHAPADÃO DO DIAMANTE, SERRA DA CANASTRA - MG: UM OLHAR SOBRE A GEODIVERSIDADE
}

\author{
Thallita Isabela Silva Martins Nazar ${ }^{(\mathrm{a})}$, Giliander Allan da Silva ${ }^{(\mathrm{b})}$, Silvio Carlos Rodrigues ${ }^{(\mathrm{c})}$ \\ (a) Programa de Pós-Graduação em Geografia, Instituto de Geografia, UFU, thallitamartins09@gmail.com \\ (b) Programa de Pós-Graduação em Geografia, Instituto de Geografia, UFU, gili.franca@ hotmail.com \\ (c) Professor Dr. do Programa de Pós-Graduação em Geografia, Instituto de Geografia, UFU, silgel@ufu.br
}

\section{Eixo: GEODIVERSIDADE, GEOARQUEOLOGIA E PATRIMÔNIO NATURAL}

\begin{abstract}
Resumo
Este trabalho objetiva apresentar uma síntese da caracterização da geodiversidade do Chapadão do Diamante $(\mathrm{ChD})$, tendo como base os aspectos litológicos e geomorfológicos, bem como, os aspectos bióticos, na busca de uma maior valorização e entendimento da área. Foram realizados diversos trabalhos de campo e feita revisão teórica pertinente para a caracterização e levantamentos de dados do ChD. A área corresponde à superficie da Serra da Canastra em sua porção oriental, e faz parte do Parque Nacional da Serra da Canastra. Apresenta beleza cênica de grande exuberância, estruturada pelos quartzitos do Grupo Canastra, que formam escarpas abruptas nas bordas e um relevo diversificado em seu interior. Observa-se diferentes padrões de paisagem, que podem ser definidos de forma geral a partir dos aspectos topográficos, de materiais superficiais e tipos de vegetação.
\end{abstract}

Palavras chave: PARNA Canastra. Paisagem quartzítica. Relevo Serrano.

\section{Introdução}

O Chapadão do Diamante $(\mathrm{ChD})$ corresponde à superfície de cimeira da Serra da Canastra, em sua porção oriental. É caracterizado por uma morfologia diversificada resultante da atuação de processos geomórficos ao longo do tempo geológico sobre uma estrutura embasada, predominantemente, por rochas quartzíticas. A sua composição paisagística oferece grande exuberância do ponto de vista da geodiversidade, uma vez que é circundado por escarpas abruptas, onde correm inúmeras quedas d'água, abastecidas marcante presença hídrica observada em sua superfície.

A paisagem do $\mathrm{ChD}$ torna-se de grande interesse devido à sua intrínseca dinâmica. Observa-se na paisagem a ocorrência de superfícies aplanadas, vales encaixados com profundos depósitos aluviais e morros quartzíticos com depósitos de tálus. Ademais, há marcas relacionadas à atividade estrutural (possível neotectônica), tais como lineamentos de feições e linhas de fraturas, condicionando uma dinâmica hídrica peculiar, com padrões de drenagem tipo retangular e paralela. Tais configurações mostram a importância do aprofundamento dos estudos acadêmicos, o que deve corroborar para o 


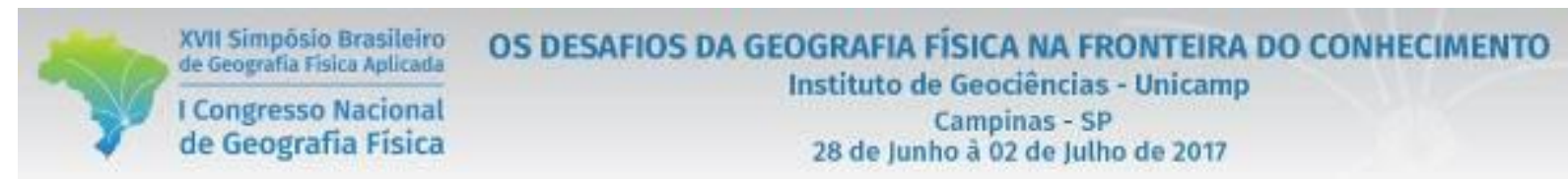

enriquecimento científico sobre a área, atualmente, carente de trabalhos voltados especificamente à análise da geodiversidade.

Este trabalho tem o objetivo de apresentar uma síntese da caracterização da geodiversidade do $\mathrm{ChD}$, tendo como base os aspectos litológicos e geomorfológicos, bem como, os aspectos bióticos, na busca de uma maior valorização e entendimento da área. Disserta-se a partir das observações de campo realizadas durante várias campanhas, entre abril de 2014 a janeiro de 2017, associadas ao levantamento bibliográfico pertinente.

A área de estudo integra o Parque Nacional da Serra da Canastra (PARNA Canastra), que foi criado no ano de 1972 (MMA/IBAMA, 2005), época na qual era ocupado predominantemente por atividades voltadas à pecuária extensiva. Hoje, aproximadamente $40 \%$ da área encontra-se desapropriada e controlada pelo ICMBio, enquanto o restante, apesar de pertencer ao parque, ainda é ocupada com atividades agropecuárias de uso restrito. Conforme apresenta o Mapa 1, a área de estudo localiza-se a sudoeste do Estado de Minas Gerais, no município de São Roque de Minas, assentada na porção meridional do Cinturão Orogênico Brasiliano (TOMAZZOLI, 1990; SOUZA; RODRIGUES, 2014).

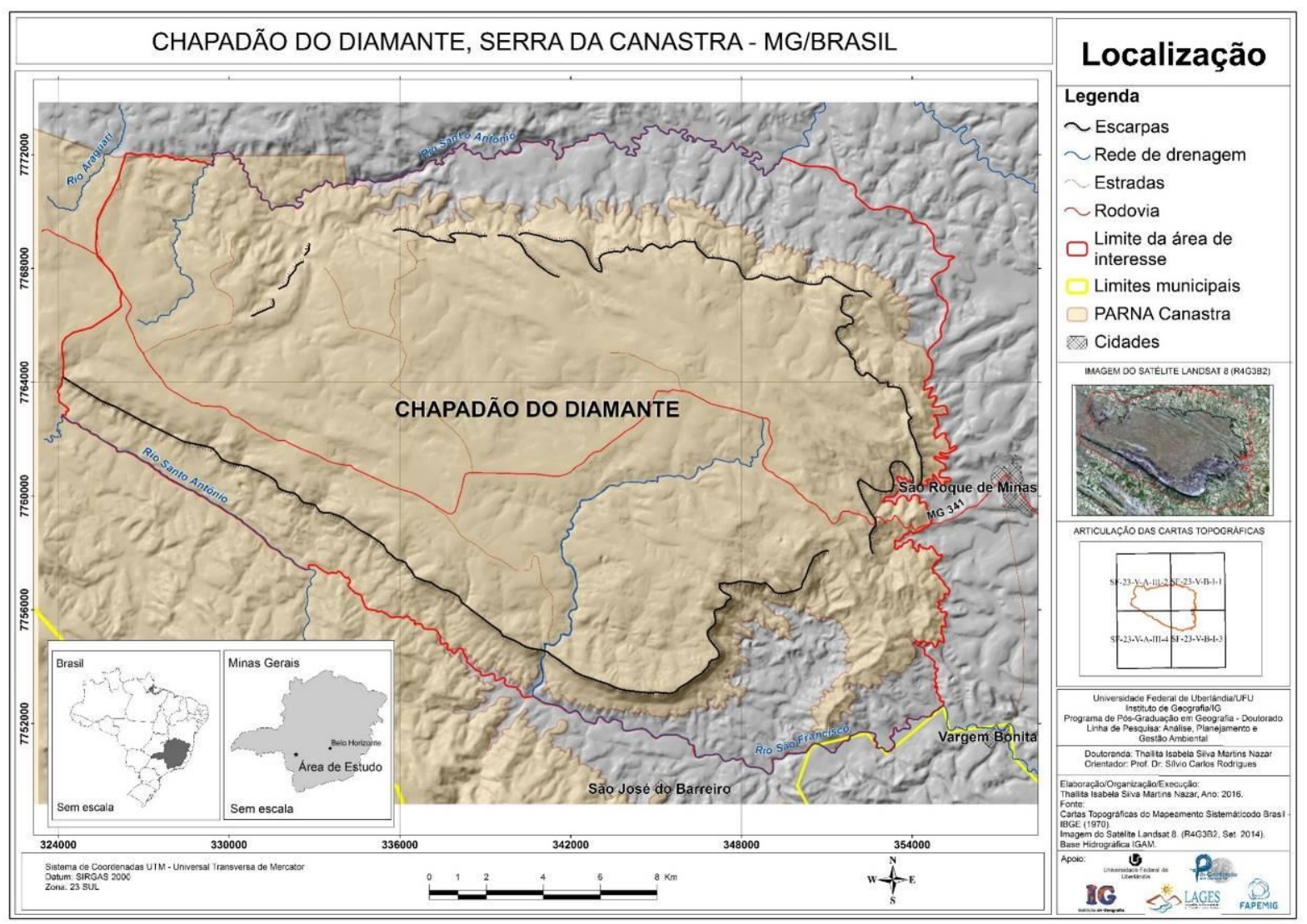

Mapa 1: Localização da área de estudo. Autoria: NAZAR, T. I. S. M., 2017. 


\section{Procedimentos operacionais}

A análise da paisagem empreendida neste estudo pode ser dividida em duas abordagens principais. A abordagem direta diz respeito à realização de trabalhos de campo, para reconhecimento e observação da paisagem, no que se refere aos fenômenos geomorfológicos, dinâmicas hídricas e biológicas. Já a abordagem indireta se refere à pesquisa teórica, que inclui o levantamento bibliográfico acerca dos assuntos pertinentes ao tema e à área de estudo. O Quadro 1 lista os trabalhos de campo realizados e os seus objetivos.

Quadro 1: Trabalhos de Campo realizados.

\begin{tabular}{|c|c|}
\hline Período & Objetivos \\
\hline Abril/2014 & $\begin{array}{r}\text { Reconhecimento da área (setor Leste), registro fotográfico, } \\
\text { observações, registro de pontos GPS. }\end{array}$ \\
\hline Fevereiro/2015 & $\begin{array}{r}\text { Reconhecimento da área (setor Oeste), registro fotográfico, } \\
\text { observações, registro de pontos GPS. }\end{array}$ \\
\hline Junho/2015 & $\begin{array}{r}\text { Reconhecimento da área (setor N e S), registro fotográfico, } \\
\text { observações, registro de pontos GPS. }\end{array}$ \\
\hline Fevereiro/2016 & $\begin{array}{r}\text { Registro fotográfico, observações, registro de pontos GPS, coleta } \\
\text { de materiais inconsolidados. }\end{array}$ \\
\hline Outubro/2016 & $\begin{array}{r}\text { Registro fotográfico, observações, registro de pontos GPS, coleta } \\
\text { de materiais inconsolidados. }\end{array}$ \\
\hline Janeiro/2017 & Registro fotográfico por sobrevoo de drone. \\
\hline
\end{tabular}

\section{Resultados}

O ChD destaca-se por abranger nascentes de duas grandes bacias, como as do Rio São Francisco (incluindo a nascente histórica) e do Rio Paraná, e constitui-se como uma larga cabeceira de drenagem de notória importância no cenário hidrológico regional (MAPA 2). Situa-se em uma região de clima Tropical típico, com duas estações bem definidas; sendo a úmida caracterizada pelo excedente hídrico no trimestre de dezembro a fevereiro; e a seca que ocorre mais acentuada entre junho e agosto, sendo estes também os meses mais frios. A pluviosidade varia entre os 1000 e $1500 \mathrm{~mm}$ e a temperatura média fica entre os $18^{\circ} \mathrm{C}$ no mês mais frio e os $22^{\circ} \mathrm{C}$ no mês mais quente (NOVAIS, 2011). Pertence ao Domínio Morfoclimático do Cerrado, apresentando variações fitofisionômicas desde campos limpos, sujos, rupestres a formações de cerrado strictu sensu e matas de galeria, especialmente condicionada pela presença de água, espessura de material inconsolidado e a altitude (MMA/IBAMA, 2005). 

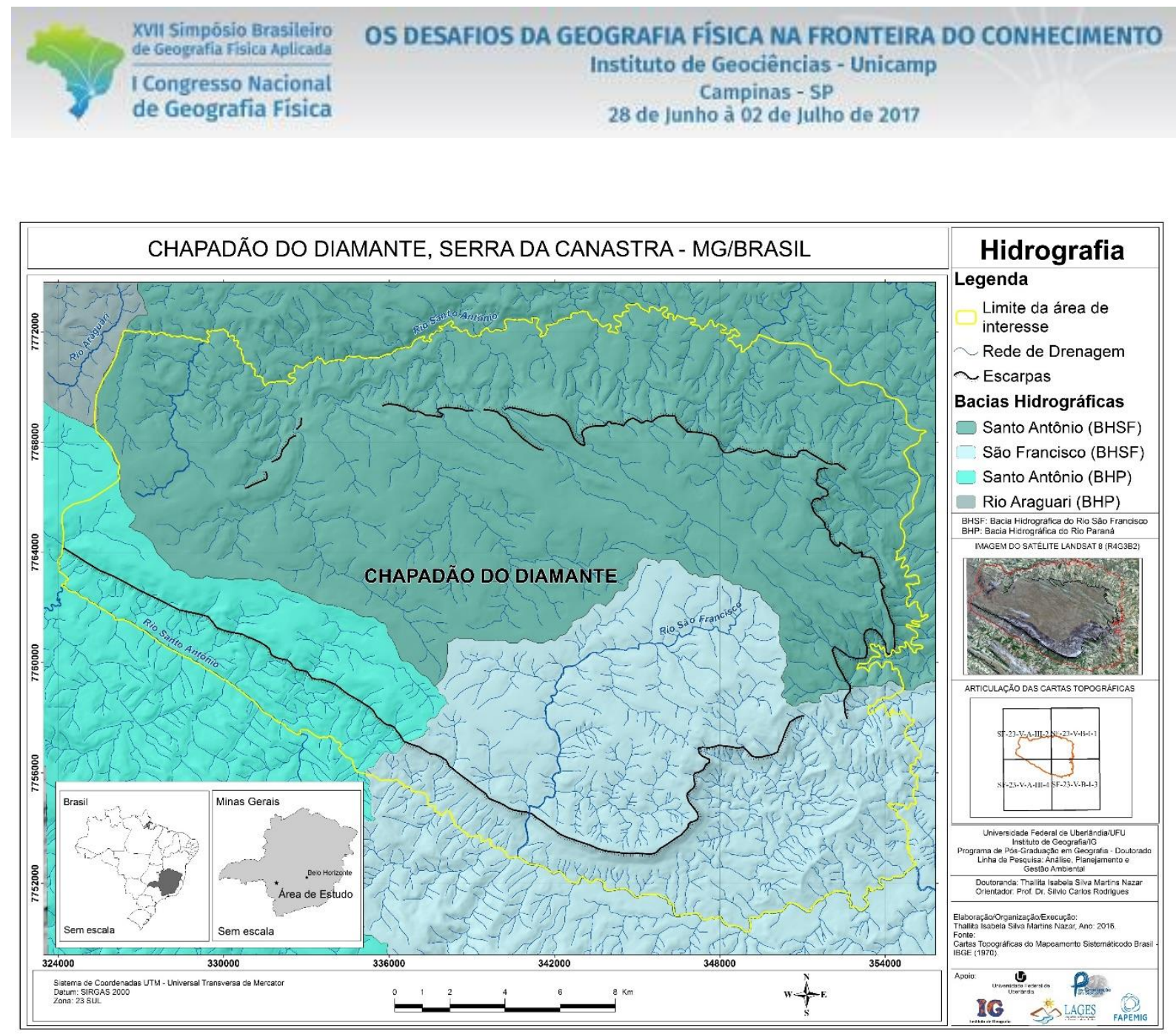

Mapa 2: Bacias Hidrográficas da área de estudo e entorno (BHSF: Bacia Hidrográfica do São Francisco; BHP: Bacia Hidrográfica do Paraná). Autoria: NAZAR, T. I. S. M., 2016.

Para a compreensão dos aspectos litoestruturais do $\mathrm{ChD}$, deve-se abordar o arcabouço geológico regional, responsável pela estruturação da Serra da Canastra, situada na porção meridional da Faixa Brasília. O ChD corresponde à superfície de cimeira dessa Serra e responde pela relação entre os aspectos geológicos e climáticos, que produz formas de relevo com características específicas capazes de demonstrar os processos que ocorreram e ocorrem nessa área.

Do ponto de vista conceitual, Valeriano et al. (2004, p. 577) afirma que a Faixa Brasília engloba "dois ramos de orientação distinta e estilos metamórfico-deformacionais contrastantes: a Faixa Brasília Setentrional (FBS), de orientação NE, e a Faixa Brasília Meridional (FBM), de orientação NW”, incluindo como áreas adjacentes o Maciço Goiano e o Arco Magmático de Goiás. Desta maneira, apropria-se da nomenclatura Faixa Brasília Meridional (FBM) para a caracterização da área de estudo, por ser a faixa onde se encontra a Serra da Canastra.

Neste sentido, a FBM engloba a faixa de relevos serranos da Serra da Canastra, situada na região oeste do estado de Minas Gerais. As litologias que caracterizam essa área são representadas pela Sinforma de 


\section{OS DESAFIOS DA GEOGRAFIA FISICA NA FRONTEIRA DO CONHECIMENTO \\ Instituto de Geociências - Unicamp \\ Campinas - SP \\ 28 de Junho à 02 de Julho de 2017}

Araxá, que consiste em uma dobra regional cujo eixo cai de modo suave para WNW, com flancos de direção WNW e mergulhos para NNE e SSW. Este evento geológico deu origem a um conjunto de três lascas tectônicas separadas por falhas de empurrão, cada qual referente aos grupos Araxá, Ibiá e Canastra, sendo que, este último, compreende a lasca tectônica inferior e engloba a área de estudo (VALERIANO et al., 2004).

Importantes considerações foram preconizadas por Simões et al. (2015) relacionadas à litoestratigrafia do Grupo Canastra, na região da Serra da Canastra. Os autores consideram a presença de escamas tectônicas de sequências metapsamopelíticas, diferenciando três conjuntos independentes, formados pelas unidades formais Subgrupo Chapada dos Pilões e Subgrupo Paracatu, e pela unidade constituída como Grupo Canastra Indeterminado, conforme se observa na Figura 1:

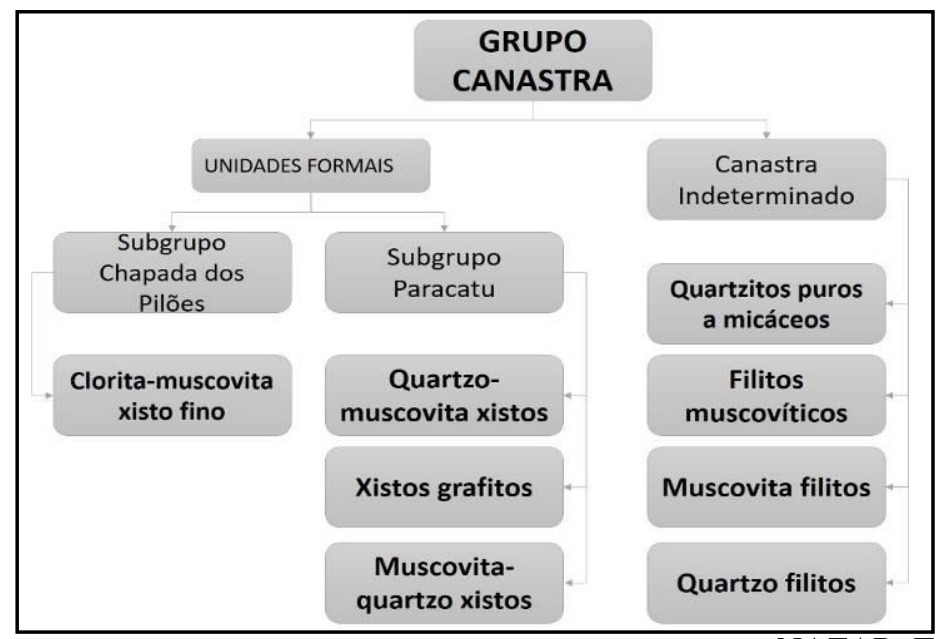

Figura 1: Fluxograma representativo do Grupo Canastra na região. Org.: NAZAR, T. I. S. M., 2017.

O Grupo Canastra Indeterminado é formado por duas unidades litoestratigráficas. A inferior é constituída por um pacote de filitos bandados intercalado por quartzitos (metarenito), enquanto a superior é composta pelo pacote de quartzitos puros a micáceos com raras intercalações de muscovita filito (SIMÕES et al., 2015). Essas unidades sustentam a Serra da Canastra, onde está assentado o ChD (Figura 2).

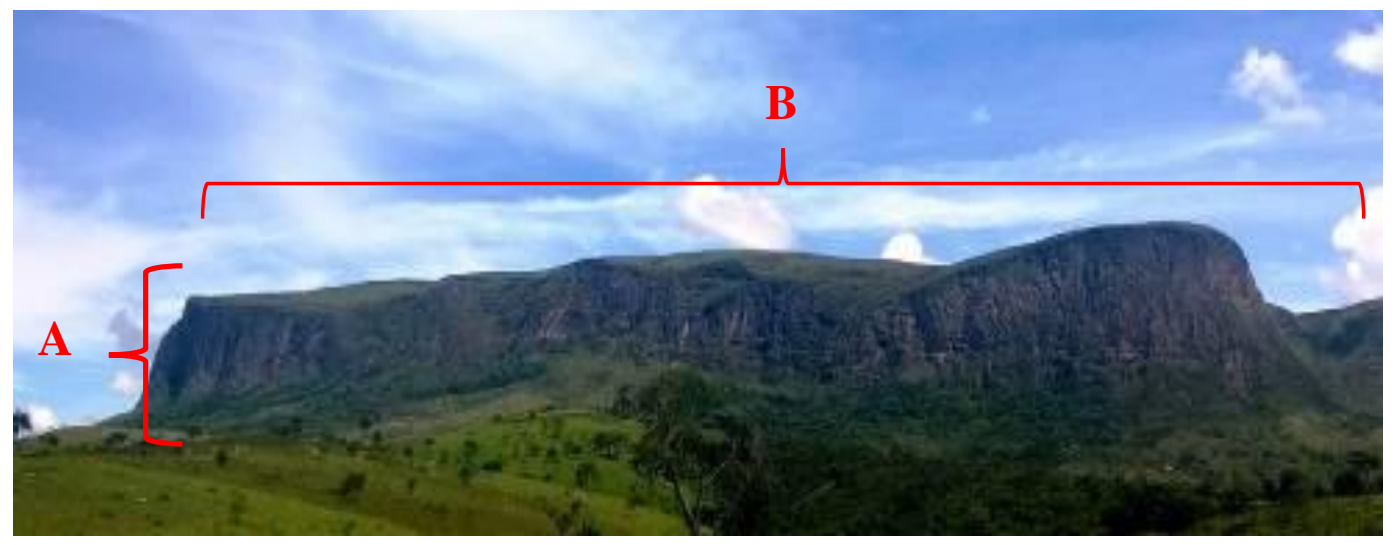




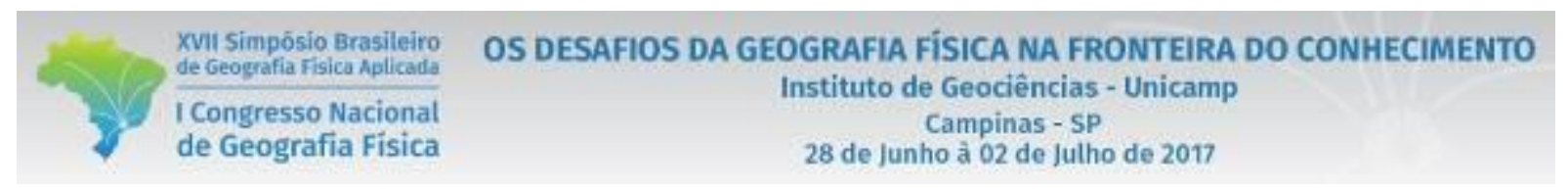

Figura 2: (A) Estrutura atribuída ao pacote de Quartzitos puros a micáceos (Grupo Canastra Indeterminado), que sustenta o ChD (B). Autoria: NAZAR, T. I. S. M., fev. 2015.

Especificamente, no que concerne aos estudos de Simões et al (2002), tendo mapeado a porção leste do ChD, o mesmo é estruturado pela Unidade de Quartzitos, possivelmente com mais de $1000 \mathrm{~m}$ de espessura, e possui as seguintes características:

- "É constituída essencialmente por quartzitos com raras ocorrências de filito.

- Variam de puro a micáceo, com predomínio dos tipos pouco micáceos e puro.

- A faixa de granulação predominante é de areia média a grossa, porém localmente ocorre areia fina.

- Os grãos são bem selecionados, arredondados a subarredondados.

- Apresentam-se em camadas marcadas pela variação do tamanho dos grãos sedimentares de quartzo e pela variação na proporção entre quartzo e mica.

- As camadas apresentam espessuras decimétricas a métricas, podendo ser maciças ou laminadas.

- Os quartzitos são brancos, assumindo coloração amarela quando alterados.

- A mica presente é muscovita e como acessórios predominam turmalina e zircão e mais raramente opacos.

- Algumas camadas, pouco frequentes, apresentam cristaloclastos de feldspato.

- Correspondem a metarenitos depositados, provavelmente em plataforma rasa, proximal.

- Em geral, a principal estrutura que se observa nessas rochas é uma clivagem ardosiana, de direção WNW e mergulhos subverticais para SSW, denominada de foliação principal (Sn)." (SIMÕES et al., 2015, p. 41-42)

No entanto, os estudos dos autores supracitados foram realizados na parte leste do ChD, restando ainda dúvidas em relação à litoestratigrafia de toda a área abordada nesta pesquisa. Características como: a distribuição das coberturas superficiais, que podem ser observadas no sentido SE-NW, com o aumento das aparições de materiais dedríticos ferrugionosos; mudanças de coloração nas fases de aprofundamento do manto de alteração, de amarelo para avermelhado; e, o caimento do relevo também no sentido SE-NW com as bordas do $\mathrm{ChD}$ com cotas topográficas mais elevadas que o interior podem ser indicativos de alterações de litologia e processos morfológicos evolutivos, porém tais aspectos fogem à alçada desta pesquisa, mas são válidas estas observações para que trabalhos mais verticalizados possam surgir na área, por profissionais especializados.

O perfil topográfico apresentado na Figura 3 ilustra a característica de caimento do relevo. É possível observar as áreas mais elevadas no setor SE, com presença marcante de afloramentos rochosos e morros com declividades maiores, enquanto a topografia se torna mais suave em direção a NW, tendo sido verificada a mudança nas coberturas superficiais. As imagens (Figura 4) demonstram os afloramentos rochosos presentes abundantemente nas áreas mais elevadas e também nos fundos dos vales, podendo ocorrer de forma esparsa em várias áreas de toda a superfície do ChD. 
XVIı Simpósio Brasileiro de Geografia Fisica Aplicada

I Congresso Nacional de Geografia Fisica
OS DESAFIOS DA GEOGRAFIA FISICA NA FRONTEIRA DO CONHECIMENTO

Instituto de Geociências - Unicamp

Campinas - SP

28 de Junho à 02 de Jutho de 2017

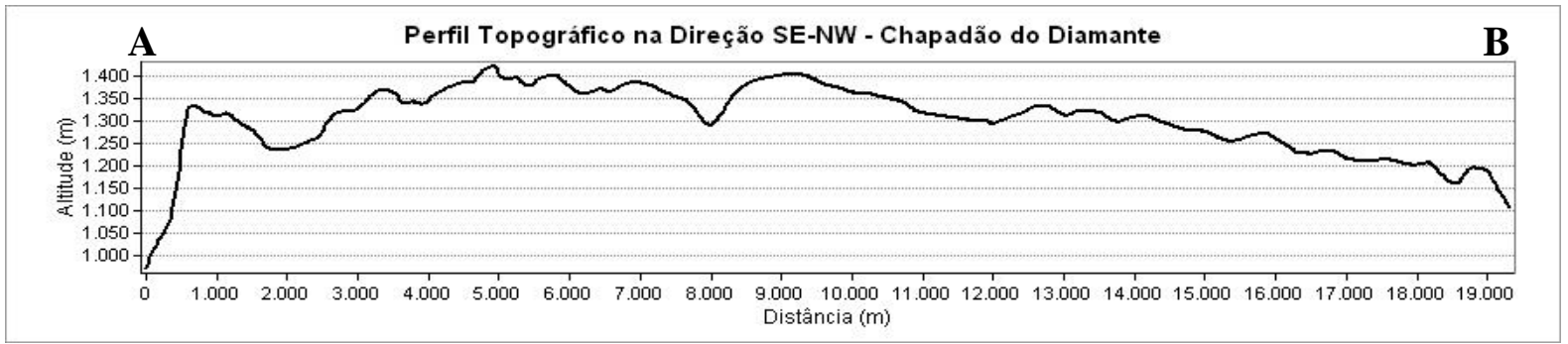

Figura 3: Perfil Topográfico do ChD. Org.: NAZAR, T. I. S. M., 2017.

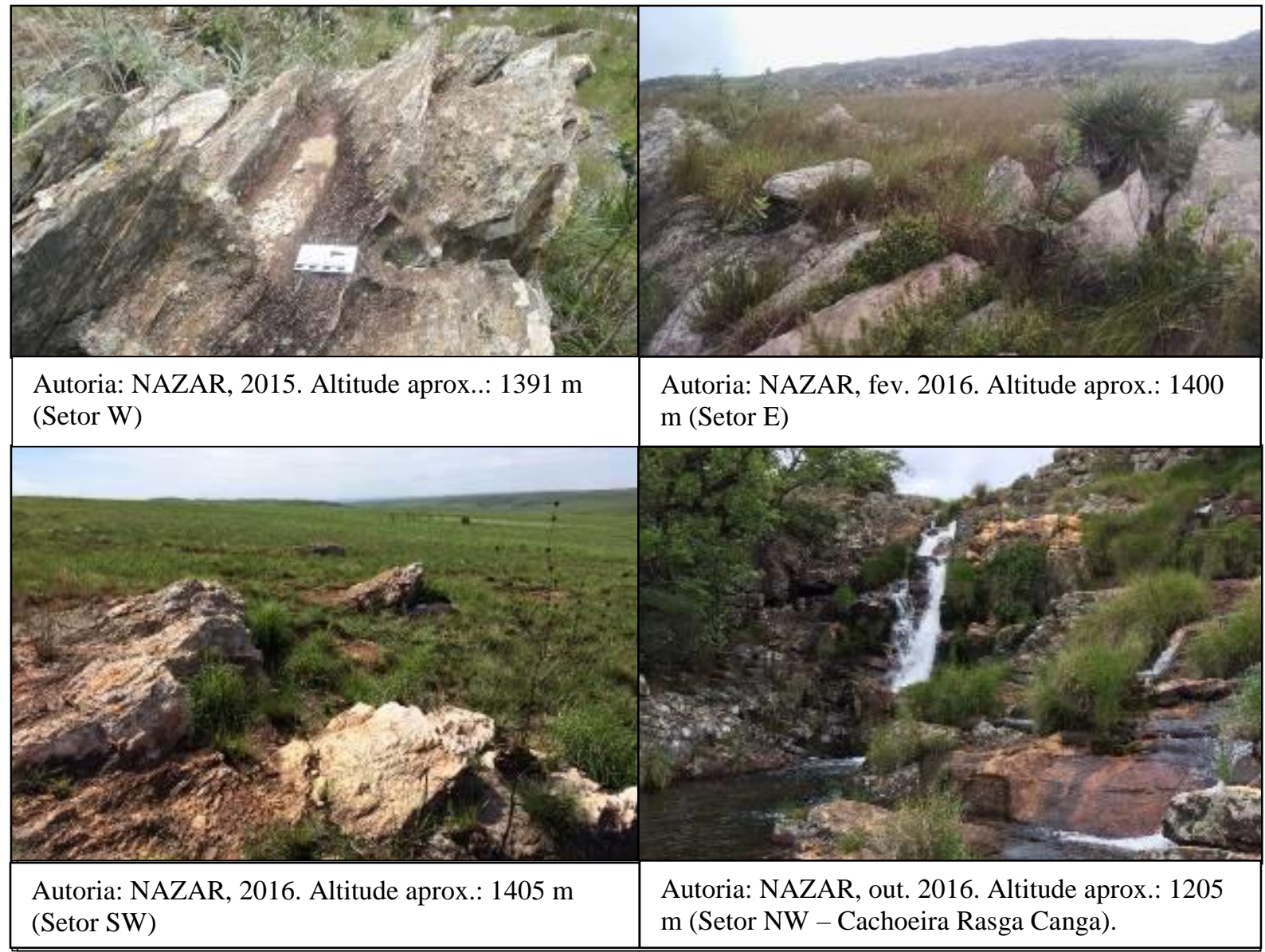

Figura 4: Afloramentos rochosos no ChD.

Do ponto de vista geomorfológico, a caracterização e o entendimento de tais aspectos no ChD perpassam pela compreensão da morfoestrutura e dos aspectos morfoesculturais que se destacam na configuração geral da área. Neste sentido, o ChD possui como base o arcabouço que sustenta a Serra da Canastra, derivada dos processos que formaram a Faixa Brasília Meridional e o Grupo Canastra, ao longo de 


\section{OS DESAFIOS DA GEOGRAFIA FISICA NA FRONTEIRA DO CONHECIMENTO \\ Instituto de Geociências - Unicamp \\ Campinas - SP \\ 28 de Junho à 02 de Julho de 2017}

milhares de anos. As rochas quartzíticas que o compõem são mais resistentes ao intemperismo, e mesmo

em regiões tropicais, cuja atuação de um clima mais úmido incrementa os processos de dissecação do relevo, a intensidade desses processos acontece mais lentamente.

Sob essa perspectiva, pode-se afirmar que as formas de relevo que sobressaem no $\mathrm{ChD}$ variam entre topos planos, colinas suaves e onduladas a fortemente onduladas, bem como, morros com presença marcante de afloramentos quartzíticos e escarpas rochosas exuberantes, em altitudes que variam acima de 1080 metros, podendo chegar a 1490 metros nos picos mais elevados. Neste sentido, ao tratar dos padrões de relevo do $\mathrm{ChD}$, observa-se estreita relação entre o substrato rochoso e a topografia, juntamente com os materiais superficiais que respondem a essa interação. Os diversos trabalhos de campo realizados permitiram a observação de padrões paisagísticos que compõem um mosaico bastante peculiar na superfície do ChD. Tais padrões podem ser sintetizados em:

a) Primeiro Padrão: afloramentos quartzíticos, vertentes mais íngremes, materiais superficiais incipientes (ora com presença de cascalhos, ora com material mais fino), a vegetação é composta predominantemente por campos rupestres (Figura 5).

b) Segundo padrão: relevos suaves a ondulados, com ou sem ocorrência de campos de murundus em posições topográficas diferentes, associados, geralmente, à formação de concreções ferruginosas, com esparsos afloramentos rochosos. Os materiais superficiais variam a espessura ao longo das vertentes, caracterizando-se como rasos e pouco profundos. Predomínio de vegetação rasteira, variando entre campos limpos e campos sujos (Figura 6).

c) Terceiro padrão: também em relevos suaves a ondulados, com ocorrência de material espesso na cor avermelhada e com presença de concreções ferruginosas, em área mais afastada dos afloramentos quartzíticos e em cotas topograficamente inferiores aos padrões anteriores. Observase a ocorrência de vegetação mais densa, com presença de arbustos e árvores, característicos de cerrado stricto sensu, e nos fundos dos vales, formam-se matas de galerias (Figura 7). 
XVII Simpósio Brasileiro de Geografia Fisica Aplicada

I Congresso Nacional de Geografia Fisica
OS DESAFIOS DA GEOGRAFIA FISICA NA FRONTEIRA DO CONHECIMENTO

Instituto de Geociências - Unicamp

Campinas - SP

28 de Junho à 02 de Julho de 2017

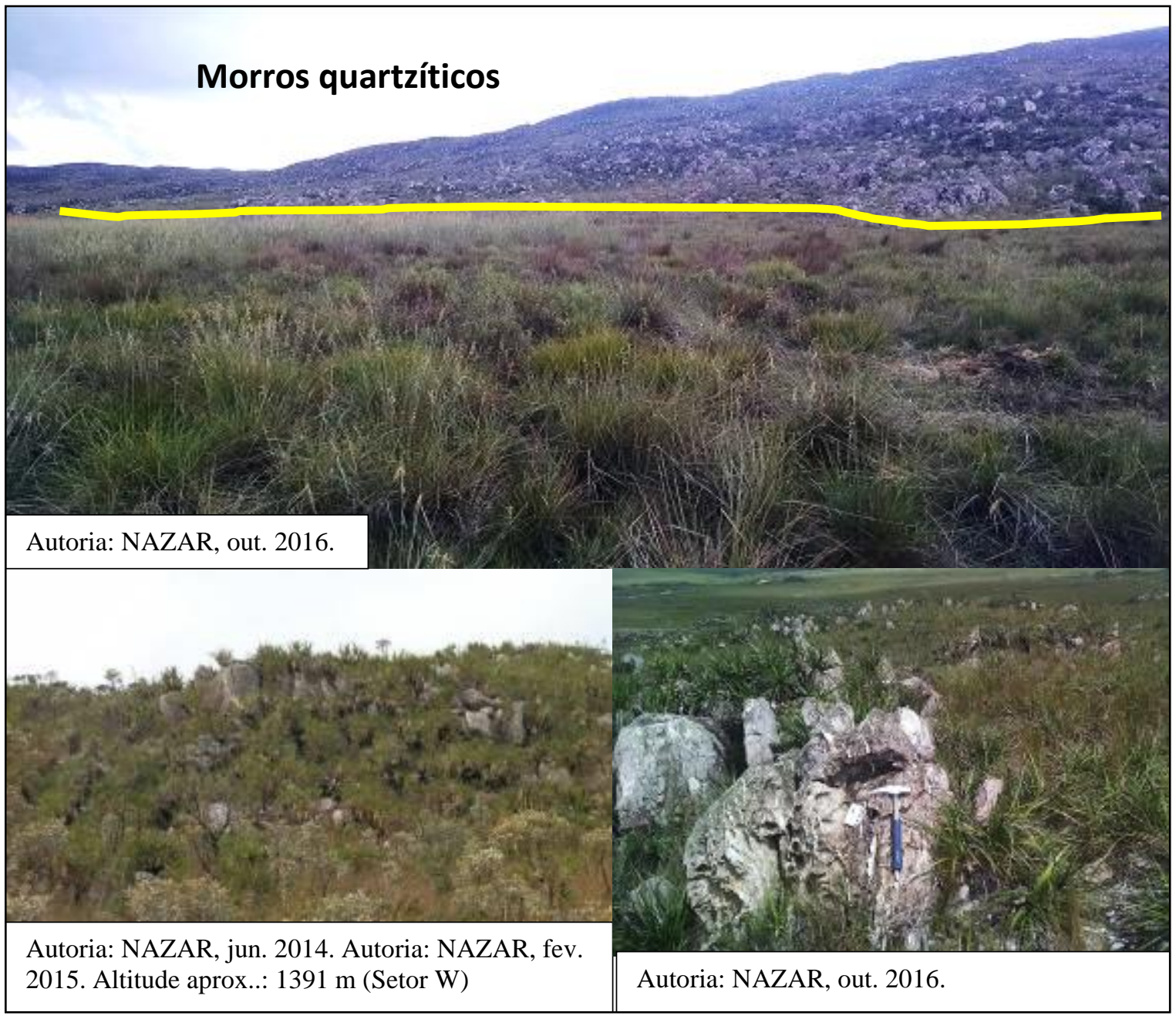

Figura 5: Padrão em morros com afloramentos quartzíticos, predomínio de campos rupestres e materiais superficiais incipientes. 


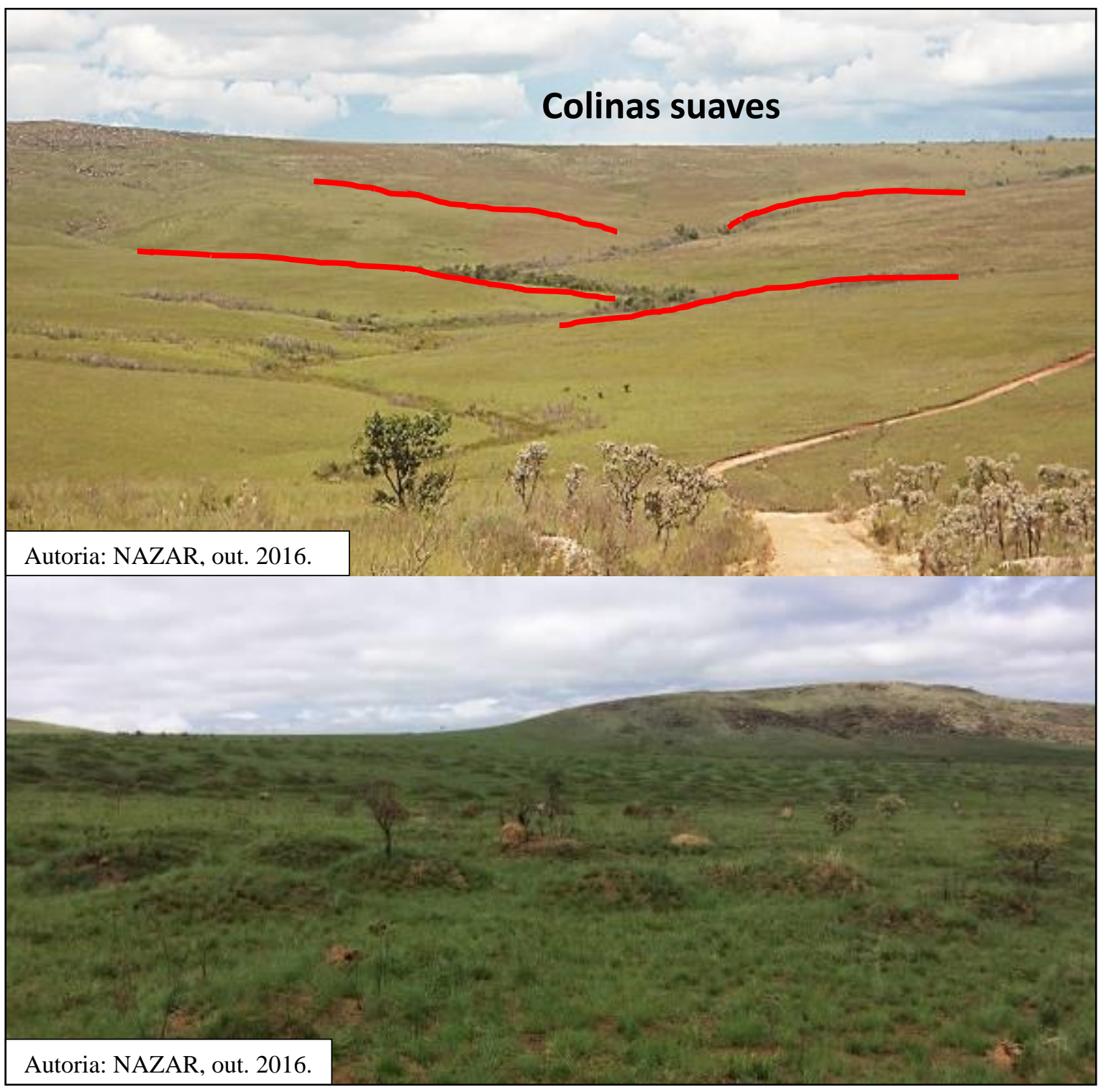

Figura 6: Padrão em colinas suaves a onduladas, com predomínio de campos limpos ou sujos e ocorrências de campos de murunduns. 


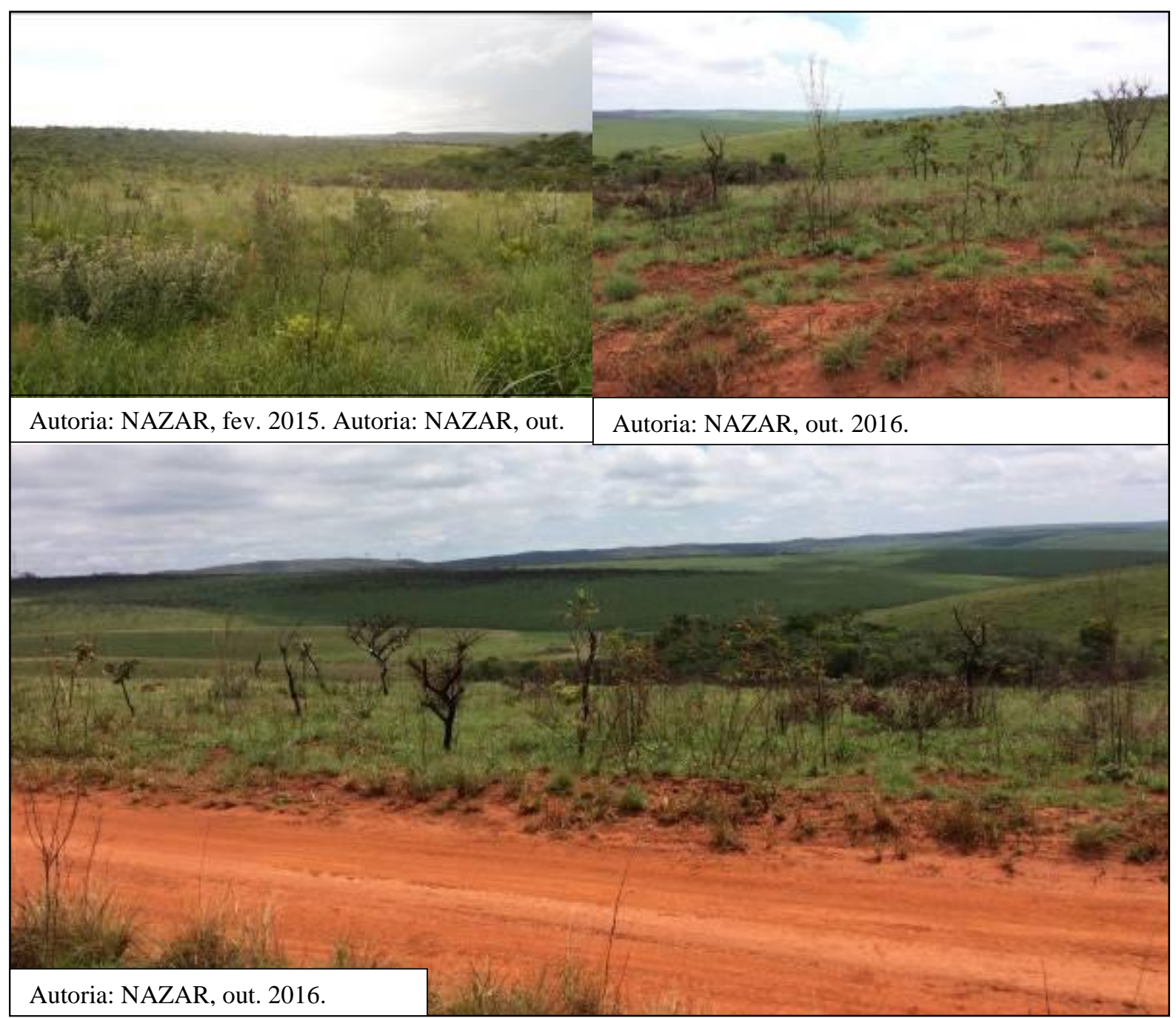

Figura 7: Padrão em relevos suaves a ondulados, com ocorrência de material espesso na cor avermelhada e com presença de concreções ferruginosas, vegetação mais densa em algumas áreas.

\section{Considerações Finais}

Diante do apresentado, acredita-se que o Chapadão do Diamante apresenta uma rica geodiversidade, pois os dados levantados e as observações demonstram que a área vai muito além do que o nome Chapadão pode remeter. A nomenclatura Chapadão do Diamante é um termo genericamente atribuído em conformidade com a cultura regional, por se pronunciar como uma vasta área horizontal (IBAMA, 2005), entretanto, uma vez que é formado não apenas por áreas de topo planas, mas também por vertentes inclinadas e cristas alongadas, quando se observa localmente; oferece uma maior riqueza de detalhes, que necessita ser reconhecida, valorizada e melhor investigada. 


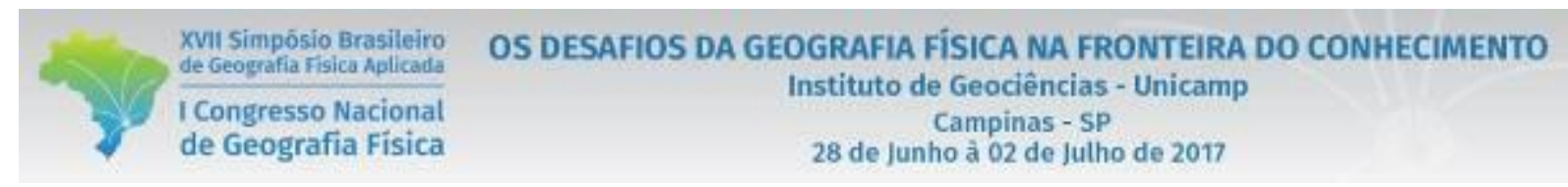

Em suma, além dos aspectos geomorfológicos peculiares, as variações vegetativas e de coberturas superficiais oferecem um conjunto de paisagens distintas que revelam diferentes processos geomorfológicos, biogeográficos e hidrológicos que necessitam maior aprofundamento nas pesquisas, tendo em vista o avanço do conhecimento científico sobre a área, o que tende a subsidiar o incremento da valorização e reconhecimento da geodiversidade local.

\section{Agradecimentos}

Os autores agradecem à Fundação de Amparo à Pesquisa do Estado de Minas Gerais - FAPEMIG pelo apoio para a participação neste evento, bem como, pelo projeto CRA APQ-00231-16 que apoia a realização da pesquisa. Além disso, a primeira autora agradece pela bolsa de Doutorado fomentada também pela FAPEMIG (PAPG - GEOGRAFIA, 2014-2018), e o segundo autor agradece à CAPES pela concessão da bolsa de Doutorado.

\section{REFERÊNCIAS}

MMA/IBAMA. Plano de Manejo da Serra da Canastra. 2005. Disponível em: <http://www.icmbio.gov.br/portal/images/stories/imgs-unidades $\quad$ coservacao $\quad$ /PM _ _PNSC_ Resumo_Executivo.PDF>. Acesso em: 20 mai. 2012.

NOVAIS, G.T. Caracterização climática da mesorregião do Triângulo Mineiro/Alto Paranaíba e do entorno da Serra da Canastra, MG. 2011. 175 f. Dissertação (mestrado). Universidade Federal de Uberlândia. Programa de Pós Graduação em Geografia. Uberlândia, 2011.

SIMÕES, L. S. A.; MARTINS, J. E. S.; VALERIANO, C. M.; GODOY, A. M.; ARTUR, A. C. Folha Vargem Bonita: SF.23-V-B-I. Programa Mapeamento Geológico do Estado de Minas Gerais. Projeto Fronteira de Minas Gerais. CODEMIG. UFMG. Ago/2015.

SOUZA, D. A.; RODRIGUES, S. C. Aspectos Morfoestruturais e Morfoesculturais da Serra da Canastra e Entorno (MG). Revista do Departamento de Geografia -USP, v. 27, p. 47-66, 2014.

TOMAZZOLI, E. R. A evolução geológica do Brasil-Central. Revista Sociedade e Natureza, Ano 2, n. 3, p. 11-26, Junho 1990.

VALERIANO, C. M.; DARDENE, M. A.; FONSECA, M. A.; SIMÕES, L. S. A.; SEER, H. J. A evolução tectônica da Faixa Brasília. In: MANTESSO-NETO, V. et al. (Org.). Geologia do continente sul-americano: evolução da obra de Fernando Flávio Marques de Almeida. São Paulo: Beca, 2004. p. 575-592. 